\title{
Honesty Pledges for the Behaviorally-based Regulation of Dishonesty
}

\author{
Eyal Pe'er, School of Public Policy, Hebrew University of Jerusalem, Israel, \\ corresponding author, eyal.peer@mail.huji.ac.il \\ Yuval Feldman, Faculty of Law, Bar-Ilan University, Israel, \\ Yuval.Feldman@biu.ac.il
}

\begin{abstract}
A common dilemma in regulation is determining how much trust authorities can place in people's self-reports, especially in regulatory contexts where the incentive to cheat is very high. In such contexts, regulators, who are typically risk averse, do not readily confer trust, resulting worldwide in excessive requirements when applying for permits, licenses, and the like. Studies in behavioral ethics have suggested that asking people to ex-ante pledge to behave ethically can reduce their level of dishonesty and noncompliance. However, pledges might also backfire by allowing more people to cheat with no real sanctions. Additionally, pledges' effects have only been studied in one-shot decision making, and they may only have a short-term effect that could decay in the long run, leading to an overall erosion of trust. We explored the interaction of pledges with sanctions and the decay of their effects on people's honesty by manipulating whether pledges were accompanied by sanctions (fines) and testing their impact on sequential, repeated ethical decisions. We found that pledges considerably and consistently reduced dishonesty, and this effect was not crowded out by the presence of fines. Furthermore, pledges seem to exert an effect on most people, including those who are relatively less inclined to follow rules and norms. We conclude that pledges could be an effective tool for the behavioral regulation of dishonesty, reduce the regulatory burden, and build a more trusting relationship between government and the public, even in areas where incentives and opportunities to cheat are high.
\end{abstract}




\section{Honesty Pledges for the Behaviorally-based Regulation of Dishonesty}

\section{Introduction}

The strength of regulators' efforts to control human behavior is related to the extent to which governments trust their citizens (Moyson, 2017). A common dilemma faces many policy makers: Can the public be trusted to provide accurate and honest reports of their actions, intentions, and behavior, or should the government invest resources in measures that prevent people from behaving dishonestly, often at high procedural costs and posing an increased regulatory burden (Anania \& Nisticò, 2004; Gilligan, 2018)? Since regulators tend to be risk averse, states often prefer not to confer trust upon those regulated and instead do whatever they can to prevent risks to the public interest and ensure public safety (e.g., Bews \& Rossouw, 2002; Cohn, Fehr, \& Maréchal, 2014). Their mistrust also leads governments to doubt the veracity of individuals' self-reports; this uncertainty is heightened because states cannot infer ex-ante the proportion of the population who will exploit the option to self-report fraudulently (Feldman, 2018). The end result is often a highly burdensome bureaucratic mechanism (recently termed "sludge") that reduces public risk but hampers growth (Sunstein, 2018).

One solution to this problem can be found in following the responsive regulation paradigm (Ayres \& Braithwaite, 1992) and applying findings from research on behavioral ethics (e.g., Ayal, Gino, Barkan, \& Ariely, 2015). Responsive regulation is dynamic regulatory strategy that first relies on trust between regulators and regulatees, followed by an escalation to more punitive measures if that trust is abused (Braithwaite \& Makkai, 1994). To tackle dishonesty under this paradigm, policy makers move beyond the one-size-fits-all commandand-control policies that typically require costly monitoring and enforcement and identify cases in which it could be possible to trust people and use less forceful and less coercive measures of ensuring honest and ethical conduct. An important concept is the "enforcement pyramid," 
which outlines a careful, stepped-up escalation in means used by enforcers (Ayres \& Braithwaite, 1992). Focusing first on regulatory means that allow people to feel trustworthy and that enable them to engage in voluntary compliance facilitates the formation and growth of trust (Feldman, 2018; Möllering, 2006). For example, when an entrepreneur wishes to open a new business or when citizens report their annual expenses and income for tax purposes, the government does not always have to insist that they provide all relevant materials beforehand; it does not always have to scrutinize those documents before approving their applications. In some cases, governments may simply ask applicants to testify, in advance, that their reports or applications are accurate and honest; then the state can invest more resources in auditing and sanctioning afterward. Such ex-ante honesty pledges can clearly reduce the administrative burden imposed not only on citizens but also on regulation and licensing authorities (e.g., Kucher \& Götte, 1998; Torgler, 2003).

Yet relying on pledges, rather than imposing mandatory checks, raises the risk that some people may take advantage of the situation and make false reports to claim higher benefits for themselves (Feld \& Frey, 2018). Recent research on unethical behavior has shown that indeed many people would cheat if given the opportunity (e.g., Gerlach, Teodorescu, \& Hertwig, 2019; Jacobsen, Fosgaard, \& Pascual-Ezama, 2018) and that this cheating results in excessive damage to the social fabric of society (Gächter, \& Schulz, 2016). However, some studies have suggested that making the ethical requirement more salient could reduce the likelihood that people will behave dishonestly (Bazerman \& Gino, 2012). Namely, it was found that participants claimed less unwarranted rewards in a laboratory task if the signature on the form used to claim the rewards was placed on the top instead of the bottom of the form. Shu et al (2012) found that signing at the top of a form increased the frequency of ethicality-related words in a word-completion task, suggesting participants who were asked to sign in advance had more moral concepts activated in their minds. Applying this "signing-at-the-beginning" 
design to car insurance application forms in one company resulted in claimants reporting, in their renewal application, a higher annual mileage (which results in higher premiums and thus is considered more honest; Shu, Mazar, Gino, Ariely, \& Bazerman, 2012).

However, the notion that signing reduces unethicality by invoking moral values lacks additional empirical support. First, a more recent study failed to replicate the findings in a laboratory experiment (Kristal et al., 2020) and concluded that merely changing the position of a signature on a form (from bottom to top) does not, in itself, reduce dishonesty. Furthermore, the idea for the "signing-at-the-beginning" intervention relied also on a previous study by Mazar, Amir, and Ariely (2008), which claimed that asking people to recall the Ten Commandments reduced cheating in a similar laboratory task. However, a meta-analysis of a large registered replication project of this experiment, done by 19 different labs worldwide, showed disconfirming results: in none of the cases did this type of moral reminder reduce cheating significantly, and it actually increased cheating in one case (Verschuere et al., 2018).

Pledging to behave honestly is a more heavy-handed intervention than moving the position of the signature on the form or reciting the Ten Commandments, but the research on pledges' effectiveness on reducing unethicality has been mixed and incomplete. Some research has suggested that pledges are either ineffective or even counterproductive. For example, Steen and Rutgers (2011) proposed that using an oath to enhance public service motivation might increase unethical behavior in the workplace. Additionally, pledges might, in some contexts, actually signal to people the possibility of behaving dishonestly without raising the price for doing so (Tyran \& Feld, 2006). Indeed, one recent study found that students who were asked to sign a commitment form before starting their exam actually increased their rate of cheating, measured by their propensity to give incorrect answers that were identical to those of their neighbors (Cagala, Glogowsky, \& Rincke, 2019). 
Yet, in other, mostly experimental, studies, honesty pledges have been used effectively to reduce dishonesty. Beck et al., (2018) used the "die under a cup" paradigm, in which participants roll a die secretly to determine their payment for completing the experiment (e.g., Shalvi, Eldar, \& Bereby-Meyer, 2012). They found that dishonest reporting decreased considerably when participants had to pledge in advance that the information they would provide regarding their performance during the experiment would be in line with the principle of honesty and that they would not lie to enrich themselves. Similarly, Jacquemet, James, Luchini, Murphy, and Shogren (2019) had participants sign a pledge and then play a senderreceiver game (Erat \& Gneezy, 2012) with different payoff schemes. They found that the pledge reduced the participants' lying, and the effect was significant when instructions not to lie were made explicit. Other studies also showed that ex-ante pledges can reduce biased responses to surveys (Carlsson et al., 2013; Kemper et al., 2016). Lastly, honesty oaths were sometimes effective for gaining a higher compliance rate in tax reporting (Jacquemet 2019) and within the courtroom setting (Clark 2003). Some insurance companies also include a contractual provision allowing the insurer to examine the insured under oath regarding property claims (Knoll \& Arthur 1994).

Thus, it appears that pledges could be a useful tool for regulators in their attempts to balance regulatory efficiency and the ease of doing business with the need to protect the public interest from unethical behaviors. However, the previous studies had some important limitations that prevent the direct generalization from their findings to common regulatory settings. First, all previous studies explored pledges in settings where participants could not be caught cheating, and no sanctions were implied for false pledges. Furthermore, all studies focused on one-shot single decisions and neglected to consider what happens to the effect of pledges in the long run. Thus, before we can argue for or against the use of pledges in regulation, it is critical to ascertain how, when, why, and to what extent pledges would prevent 
dishonest behavior, as well as to understand under which conditions pledges might be counterproductive and should thus be avoided. Clearly, the studies conducted to date do not yet allow us to answer these important questions.

Studying the effects of pledges would provide insights not only about how to design them in ways to maximize their efficacy but would also help determine in which conditions pledges would be most effective, so that they could achieve their ultimate aim: to contribute to building trust between generally normative people and their government. Potentially, we could then create a situation in which the regulatory burden on "good" people could be lessened without a heavy reliance on tedious bureaucratic mechanisms that reduce intrinsic compliance motivation (Bowles \& Polania-Reyes, 2012)—while not jeopardizing public safety and enabling the building of mutual trust (e.g., Hardin, 2002). In the words of President Theodore Roosevelt's, regulators could then "speak softly and carry a big stick", and may go far.

\section{The Current Research}

Our study focused on three main research questions that are both theoretically novel and significant, as well as practically important and with implications for policy. First, we empirically test and determine the effectiveness of pledges in reducing dishonesty compared to traditional measures of preventing dishonesty such as fines. Even those who believe that many people can be trusted to abide by their pledges recognize the need to maintain some monitoring mechanisms, with penalties for transgressions. Thus, it is crucial to understand the interaction between pledges and sanctions. The current research on sanctions provides evidence for two competing types of interaction effects: crowding-out and crowding-in (Bowles \& Polania-Reyes, 2012). The most common finding is that sanctions, especially if they are not strong enough, can undermine compliance by crowding out intrinsic prosocial motivations without providing a strong enough external incentive to comply (Tenbrunsel \& Messick, 1999). 
In contrast, other studies suggest that, in some contexts, incentives such as monetary rewards increase voluntary compliance and prosocial behavior (e.g., Galbiati \& Vertova, 2014). To date, studies on crowding-out have focused on altruism-participants in public good experiments helping others and giving charitable donations - and less on honesty. Studying the joint effect of incentives and pledges on honesty is hence an important step toward understanding how pledges operate in the real world.

The second focus of the current research is whether and how the effectiveness of pledges decays over time. To date, studies on the effectiveness of pledges have only examined their effects on a subsequent, single behavior. However, in many situations there are repeated opportunities to cheat, and those opportunities are in play for a considerable period of time, while the effect of the pledge might fade away or decay. Understanding the time frame of the effect of pledges on ethical behavior is crucial to understanding the nature of their effect both theoretically and from a prescriptive point of view of when pledges should be used.

Lastly, pledges may be effective only for certain people, because there could be significant heterogeneity in at least two important types of relevant individual differences. First, pledges might only affect those who cheat to a relatively small extent, because the marginal gain they could obtain from cheating would be small. In contrast, if a person wishes to increase gains by cheating to a large (or maximal) degree, pledging honesty beforehand may not have a substantial effect. Second, some people are, a priori, more willing than others to follow rules, guidelines, and regulations (e.g., Lewis et al 2009). If pledges were found to affect only those who are already relatively compliant, their merits as policy instruments might be moot. To summarize, our study extends previous findings and explores how much honesty pledges could reduce dishonesty (a) compared to fines, (b) over time, and (c) among different types of people. 


\section{Method}

Participants. We sampled 1,195 participants from Prolific Academic (http://prolific.ac), an online recruitment platform that has been shown to produce high-quality responses (e.g., Peer et al., 2017). We excluded 37 participants whose IP address appeared twice. The final sample included 1,158 participants with 54\% female. Their age ranged from 18 to 86 , with a mean of $34(\mathrm{SD}=12.3)$. Participants received $0.50 \mathrm{GBP}$ as base payment plus a bonus based on their performance in the study.

Design and Procedure. Participants were invited to a study about "problem solving" and were first given instructions about the main task they would perform: an online version of the matrices task (Mazar et al., 2008). In this task, participants are presented with a 4 x 3 table of 12 numbers, each with two decimal digits (e.g., 4.52); they have to find two numbers that, when added together, result in exactly 10 (e.g., 4.52 and 5.48). In the original paper version, participants receive 20 matrices on one sheet of paper and are given 5 minutes to solve as many problems as they can. In the online version that we created, each problem is displayed separately on a webpage with a timer of 20 seconds and two option buttons: "Found it" or "No." The option for "No" is preselected by default unless the participant changes it to "Found it" before 20 seconds elapse (see Figure 1). After 20 seconds, the page advances to the next problem. Before beginning the task, participants first read a short explanation on how to solve the matrix problem (find the two numbers that add up to 10) and are asked to summarize those instructions in their own words before proceeding. Then, participants are given a practice problem with 20 seconds to solve it (Figure 1). After 20 seconds, participants are shown a page in which they are asked to fill in the two solution numbers (e.g., 3.42 and 6.58). In the practice problem, these numbers are pre-filled to show participants the correct solution. 
Figure 1. Example of matrix problem used in the online study.

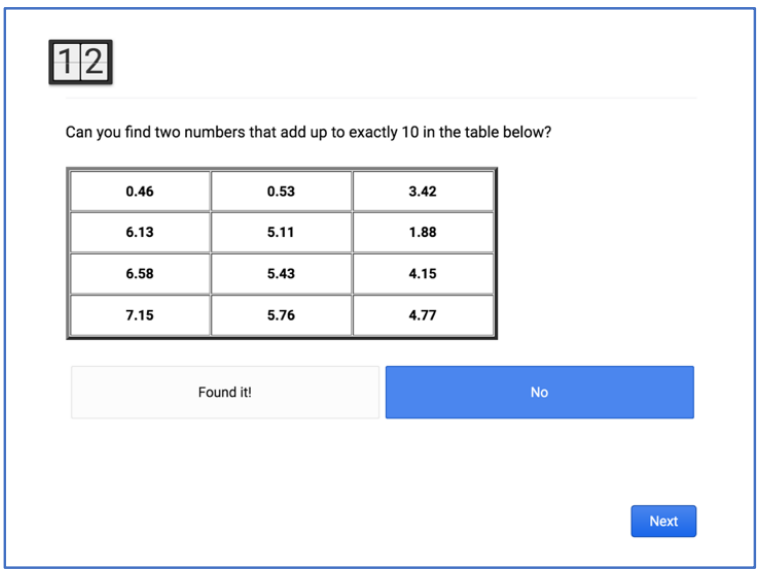

Participants were assigned to either the "Standard track" or the "Fast track". In the "Standard track", which served as the control condition, participants were asked to report, after each matrix problem, the two numbers that formed the solution (i.e., added up to 10 exactly) and received a bonus only for problems to which they provided the correct solution. In contrast, participants in the "Fast track" were asked to self-report whether they found the solution or not, with the warning that they might be asked to provide the solution numbers at a $10 \%$ probability across problems. The "Fast track" participants were randomly assigned to three pledges conditions: (1) no pledge, (2) pledge once (only before starting the task), or (3) pledge repeat (before the task plus a reminder in the middle of the task). Each of these three groups was given a different description of the fine to be administered if a problem were to be audited and the participant failed to provide a solution: (1) no fine (only lose the bonus given for that problem), (2) full fine (lose all the bonuses from all the problems), and (3) fine repeat (like the "full fine" condition plus a reminder in the middle of the task). In total, together with the control condition, the study included 10 conditions.

Participants were given 15 problems to solve, 4 of which had no actual solution. We included these problems to be able to verify that the differences found in cheating between the groups were indeed a result of participants saying they found a solution when they did not or could not. These problems were presented as the $4^{\text {th }}, 5^{\text {th }}, 12^{\text {th }}$ and $13^{\text {th }}$ in order. The order of the 
other (solvable) problems was pre-randomized. The reminder (of the pledge, the fine, or both) was always shown with the $9^{\text {th }}$ problem.

After completing the task, participants were asked a series of follow-up questions. These included rating how difficult they found the task, whether they would take the study again in the future and recommend it to others, how fair they thought the study was, how confident they were in their answers, whether they put real effort in solving the problems, whether they tried to respond honestly, and whether they believed their responses would be found to be satisfactory: all were answered according to a scale from 1 (totally disagree) to 5 (totally agree). After answering those questions, participants were asked which track they would have chosen, if they had been given the opportunity to do so, on a scale from 1 (definitely prefer the standard track), through 3 (not sure what I prefer), to 5 (definitely prefer the fast track). Participants were also asked a question that checked whether they correctly recalled the fine for incorrect answers according to their condition. About $85 \%$ of the participants recalled the fine correctly, with no statistically significant differences in recall rates between conditions: $\mathrm{x}^{2}(3)=6.48, p>0.1$. Lastly, participants completed demographic questions about their age, gender, income, education, and work status.

Lawfulness Measure in a Follow-Up Study. About 10-15 days after the study was completed, we sent invitations to all the participants to come back and complete another survey, for an additional payment of $0.5 \mathrm{GBP}$ and a potential bonus of up to an additional $0.5 \mathrm{GBP}$. Of the 1,156 in the original sample (excluding repeating IDs), 1,039 participants $(89.9 \%)$ completed the follow-up study. The distribution of returning participants was not statistically different between conditions $-\mathrm{x}^{2}(9)=15.76, p=0.07$ - and there was no significant effect of the fine or the pledge types on return rates $(p>.2)$. We asked participants to complete several questionnaires used in earlier research to measure the tendency to follow rules: Rule Orientation scale (Fine et al., 2016; 12 items, Cronbach's alpha = 0.921), Perceived Obligation 
to Obey the Law (POOL, Tyler, 2006; 6 items, Cronbach's alpha $=0.827$ ), General Neutralization Acceptance scale (Esbensen and Osgood, 1999); 9 items, Cronbach's alpha = 0.822), and Mechanisms of Moral Disengagement (Moore et al., 2012; 8 items, Cronbach's alpha $=$ 0.777). Participants also read four scenarios (from Fine et al., 2016) describing situations with temptations for unethical consumption (e.g., buy an iPad on the black market, download a software program illegally). Three of the scenarios showed adequate reliability $($ Cronbach's alpha $=0.762)$, but the last one, which was about stealing a snack from a store, showed low correlation with the others (due to a floor effect; $\mathrm{M}=1.61, \mathrm{SD}=1.34$ ), and we thus omitted it from further analyses. We computed average composite scores for each of these four scales and for the three scenarios. We expected the POOL scale to show a negative correlation with the others, because it measures when one should obey the law, whereas the others measure when might it be okay to violate the law. However, it was actually positively correlated with all others, and thus we decided to focus on the other scales as our individual differences measure. We computed an overall "lawfulness" score as the sum of the four scales (excluding POOL) and the scenarios' mean scores. Lawfulness ranged from 4-20, with an approximately normal distribution (skewness $=-0.12)$ that had a mean of $11.48(\mathrm{SD}=2.98)$ and median of 11.63 .

\section{Results}

Overall Cheating. We computed a total score of problems solved as the proportion of problems reported as solved in the "fast track" conditions, and the proportion of problems actually solved in the "standard track" condition. As Figure 2 shows, the proportion of problems solved was lowest in the control (standard track) condition $(\mathrm{M}=28.17 \%, \mathrm{SD}=18.35)$ and highest in the fast track condition that had no pledge and no fine $(\mathrm{M}=59.77 \%$, $\mathrm{SD}=25.41$ ), suggesting that participants in the latter condition cheated (over-reported) about twice as much. An ANOVA on the total score with the pledge and fine as the independent 
variables (excluding the standard track condition) showed a statistically significant effect for the pledge and the condition $-F(2,1034)=19.92,20.43$, respectively $-p<.001$, but no interaction, $F(4,917)=0.61, p=0.66$. As can be seen in Figure 2, a full fine reduced reported performance, when no pledge was requested, from $59.77 \%$ in the no-pledge no-fine condition to $47.7 \%(\mathrm{SD}=23.5)$ in the no-pledge full-fine condition; on average, this was a 12 percentage point decrease, which is about a $20 \%$ decrease in proportion. Repeating the information about the fine kept the performance rate at a similar level (47.03\%, SD=24.98). Asking for a pledge, when there was no fine, reduced reported performance in a similar degree to $48.89 \%$ ( $\mathrm{SD}=24.11)$. If the pledge was repeated, and still no fine was present, reported performance decreased even more to a rate of $45.81 \%(\mathrm{SD}=24.58)$. When both a fine and a pledge were present, the performance rate was lowest at $37.92 \%(\mathrm{SD}=21.25)$, which is about a 20 percentage-point decrease, or about a one-third decrease in proportion, compared to the condition that included no pledge and no fine. Table 1 details the relevant statistics for all conditions.

Figure 2. Percentage of problems reported between conditions

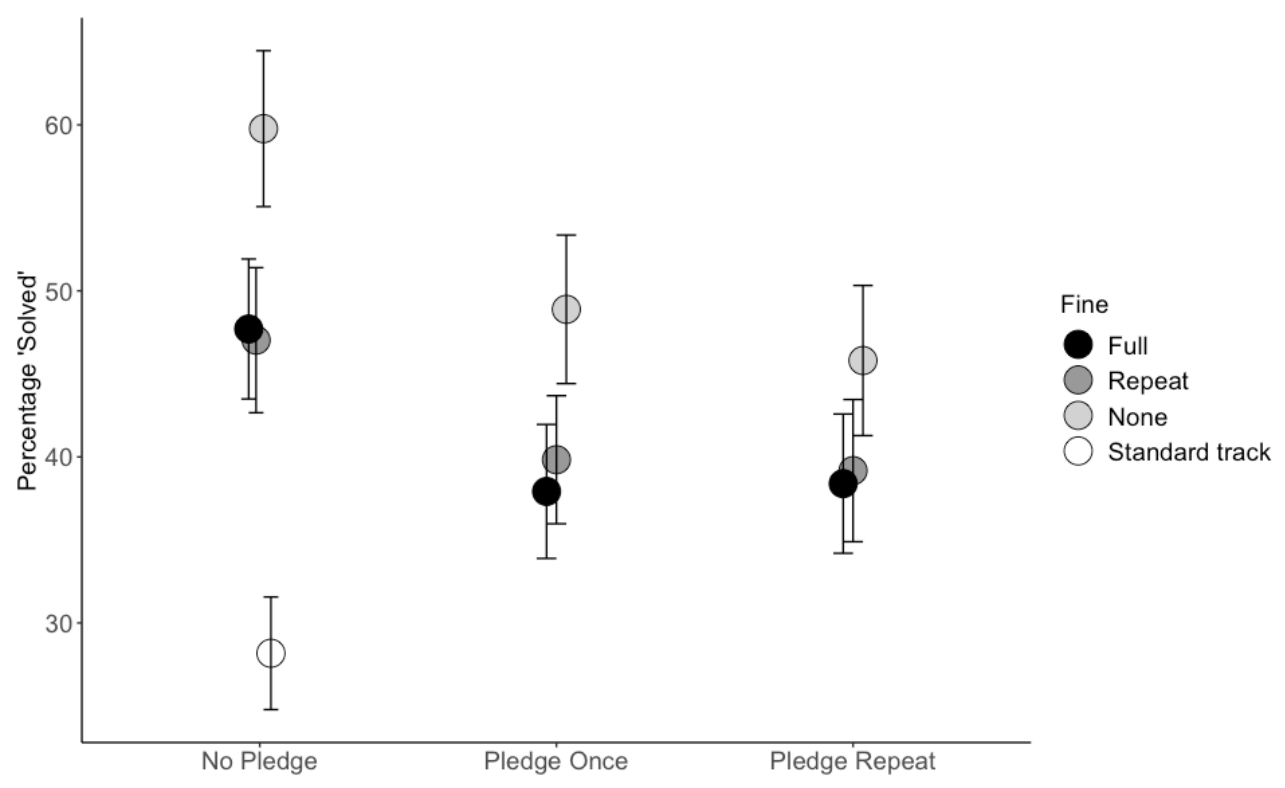

Note: Percentage of problems reported as solved in the fast track conditions, and percentage of problems actually solved correctly in the standard track; error bars indicate 95\% CI. 
Table 1. Proportion of reported performance between pledge and fine conditions, in descending order of means (cheating ratio is the proportional difference of mean cheating compared to the standard track)

\begin{tabular}{llccccc} 
Pledge & Fine & N & Mean & SD & Median & $\begin{array}{c}\text { Cheating } \\
\text { ratio* }\end{array}$ \\
\hline No & No & 94 & $\mathbf{5 9 . 8 6}$ & 25.68 & 53.33 & $200 \%$ \\
Once & No & 98 & $\mathbf{4 9 . 3 2}$ & 24.53 & 46.67 & $165 \%$ \\
No & Full & 107 & $\mathbf{4 8 . 5 4}$ & 22.94 & 46.67 & $162 \%$ \\
Repeat & No & 95 & $\mathbf{4 8 . 2 1}$ & 25.40 & 46.67 & $161 \%$ \\
No & Repeat & 115 & $\mathbf{4 7 . 7 7}$ & 25.71 & 46.67 & $160 \%$ \\
Once & Repeat & 108 & $\mathbf{3 9 . 6 9}$ & 21.25 & 33.33 & $133 \%$ \\
Repeat & Repeat & 94 & $\mathbf{3 8 . 7 9}$ & 22.29 & 40.00 & $130 \%$ \\
Once & Full & 91 & $\mathbf{3 8 . 1 0}$ & 20.78 & 40.00 & $127 \%$ \\
Repeat & Full & 99 & $\mathbf{3 7 . 2 4}$ & 21.90 & 33.33 & $125 \%$ \\
\multicolumn{2}{l}{ Standard track (control) } & 93 & $\mathbf{2 9 . 8 9}$ & 17.87 & 33.33 & \\
\hline
\end{tabular}

* Compared to the standard track (control) condition.

Robustness Check: Unsolvable Problems. As mentioned earlier, 4 of the 15 problems were unsolvable: no pair of numbers could be added to reach exactly 10 , as instructed. We examined the percent of participants reporting solving these problems separately from the other problems as a kind of robustness check for the overall cheating findings. We computed a proportion score of problems reported as solved across all four of these problems between the conditions: Figure 3 shows the differences in means between them. As can be seen, cheating was highest when there was no fine or pledge $(\mathrm{M}=0.45, \mathrm{SD}=0.39)$; adding a full fine reduced it by $0.17(\mathrm{M}=0.28, \mathrm{SD}=0.32)$. Adding a pledge, without a fine, reduced cheating slightly more by $0.19(\mathrm{M}=0.26, \mathrm{SD}=0.33)$. Repeating the pledge (still without the fine) reduced cheating a little more to $\mathrm{M}=0.23(\mathrm{SD}=0.3)$. When a pledge was taken ex-ante, adding a fine (without a reminder) had a marginal effect of reducing cheating to $M=0.15(S D=0.24)$ 
or to $\mathrm{M}=0.19(\mathrm{SD}=0.27)$ with a reminder. When the pledge had a reminder, adding a fine reduced cheating to $\mathrm{M}=0.19$ ( $\mathrm{SD}=0.27$, with or without a reminder). The overall main effect of the pledge and the fine was statistically significant, $F(2,1034)=21.6,11.91$, respectively, $p<.01$, but the interaction was not statistically significant, $F(4,1034)=1.92, p=0.1$. Again, it appears that a pledge reduced cheating significantly and considerably, even compared to a fine, and the effect of the fine was considerably diminished in the presence of a pledge.

Cheating over Time. To explore variations in cheating rates over the sequence of problems, we computed a measure of "over-report" that shows the mean difference between the percent of participants reporting the problem as solved in each condition and the actual percent of participants who correctly solved each problem. Figure 4 shows the variation of this mean difference between the conditions of the pledge. As can be seen, there was a consistently similar reduction in the cheating gap when the pledge was taken ex-ante, compared to the nopledge condition. The reminder at problem 9 seems to have had a small marginal effect, which we explore next.

Figure 3. Proportion of unsolvable problems reported as solved

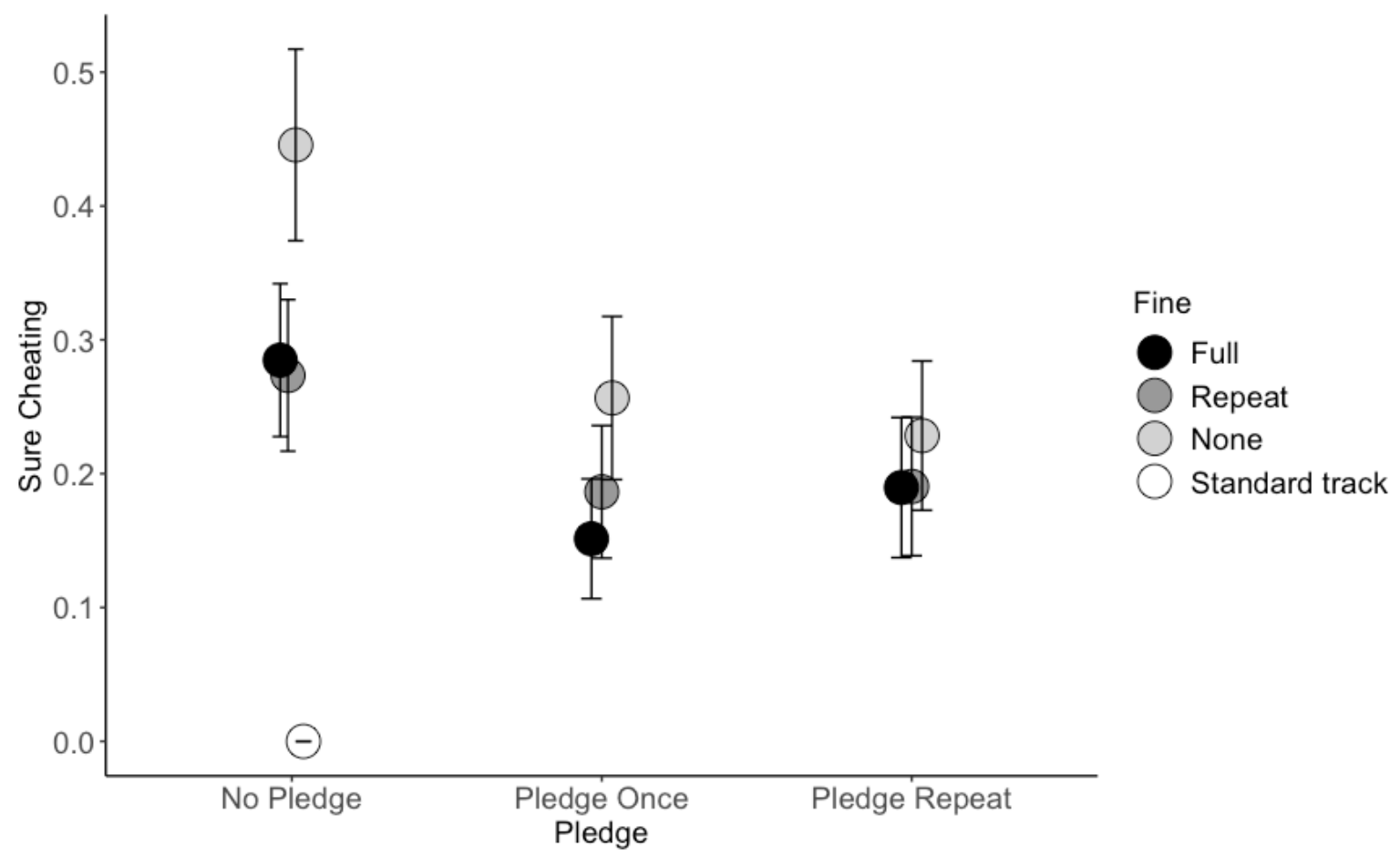


Figure 4. Mean over-report (difference compared to actual rate of correct solutions) with or without a pledge across the 15 problems

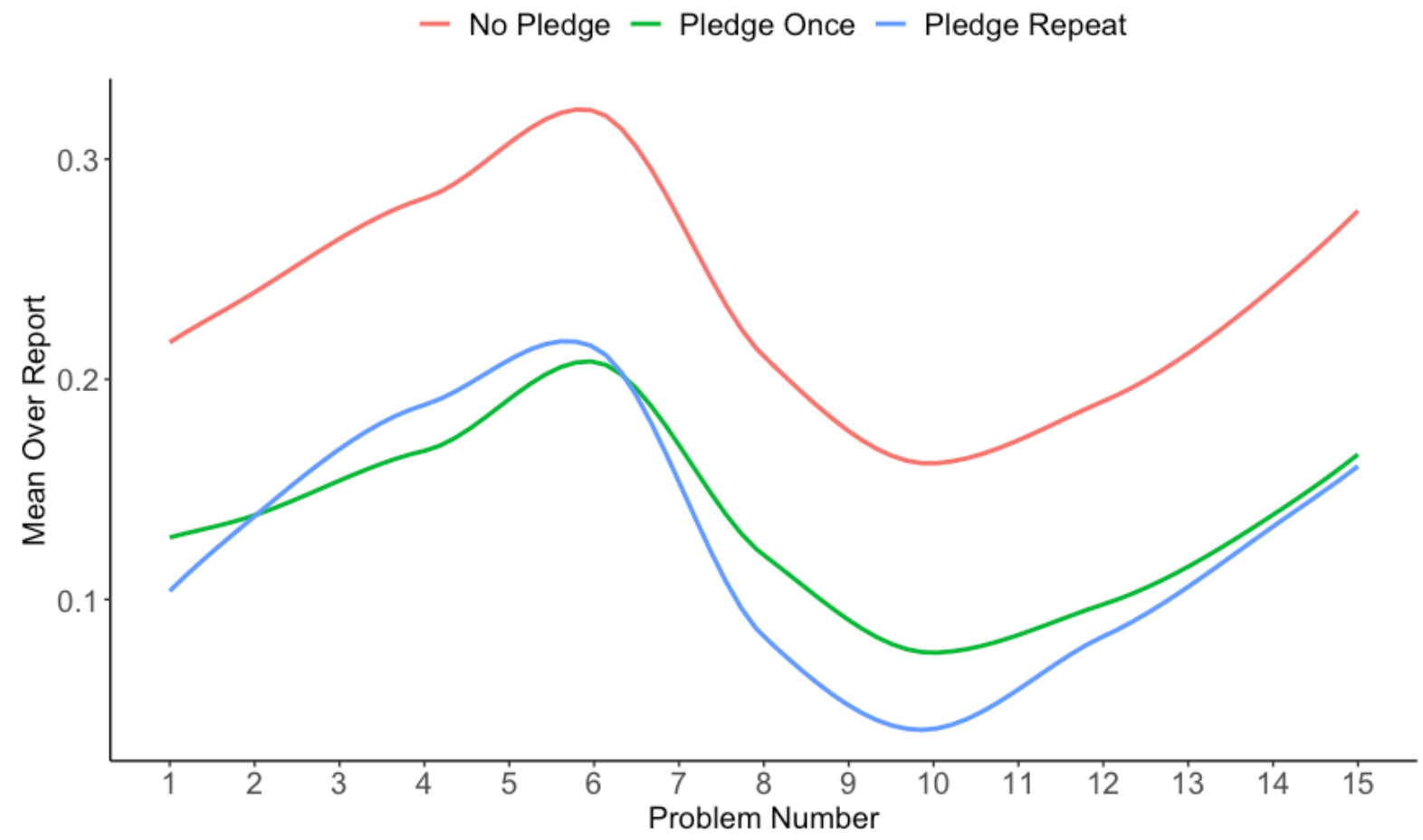

Reminder Effect. As recalled, in the "pledge repeat" and in the "fine repeat" conditions, a message appeared on the screen when the participants reached the ninth problem reminding them of their pledge and/or of the fine for incorrect responses. We examined the effect of this reminder by first computing a difference score of the average performance on problems 10 to 15 versus problems 1 through 8 , and compared these averages between all fast track conditions (we excluded problem 9 to rule out the temporary effects of a loss of attention caused by the onscreen message). Figure 5 shows the mean difference in reported performance between the conditions. As can be seen, the only case in which average performance dropped after the reminder was given was when the reminder included both the pledge and the fine $(\mathrm{M}=-0.10, \mathrm{SD}=0.24)$. We found a statistically significant interaction between the pledge and fine conditions on the mean difference, $F(4,1034)=5.19, p<.001$. 
Figure 5. Difference in mean problems solved after vs. before a reminder, between conditions (error bars show 95\% CI)

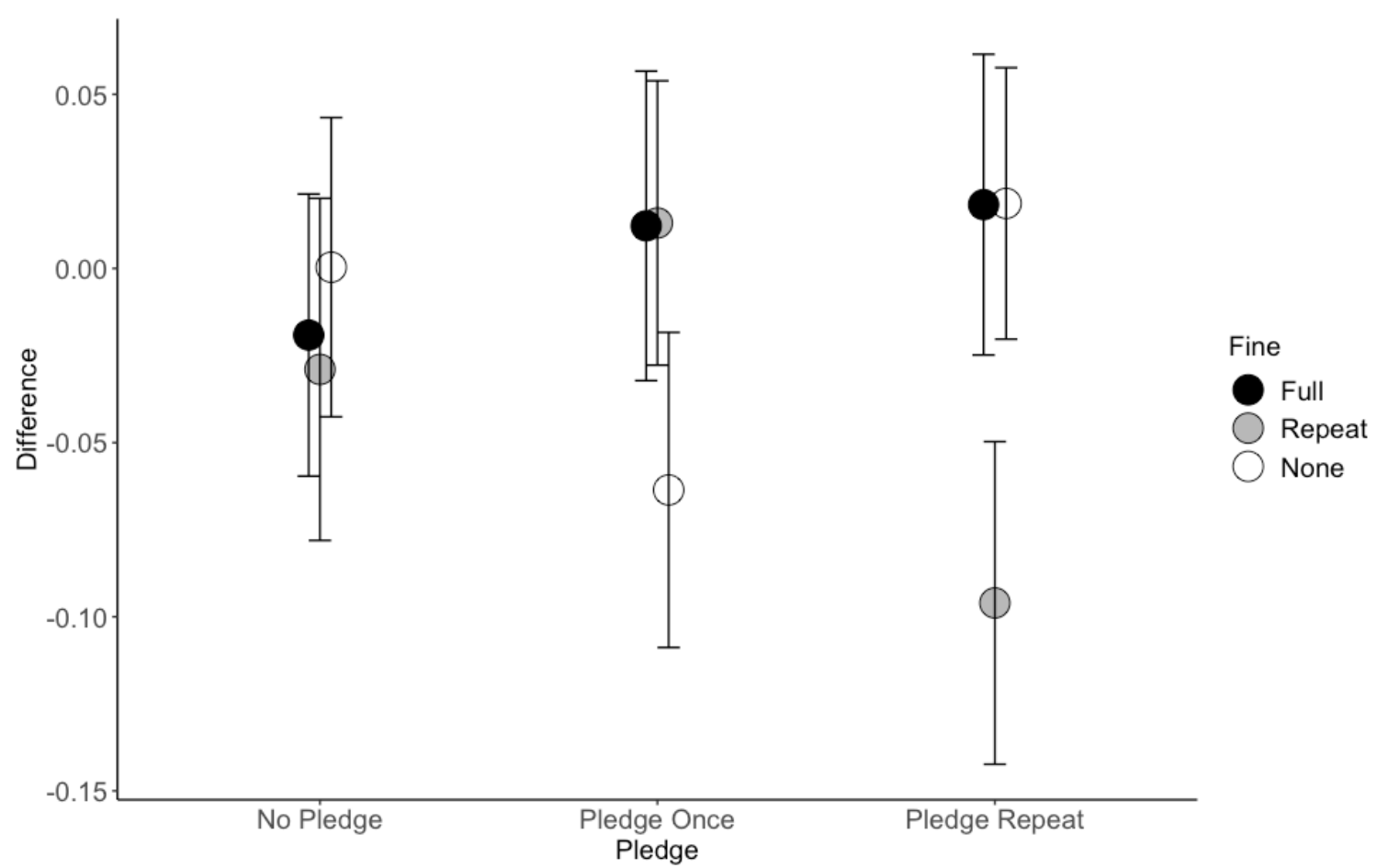

Subsequent Ratings. We found that the fine had a main effect on participants' assessments, obtained after performing the task, that they had (1) "put real effort" in their responses and (2) they "tried to respond honestly." In both ratings, participants in the fine conditions (with or without a reminder) showed higher means, $F(2,672)=3.85,3.86$, respectively, $p=0.02$. We found no effect for the pledge or the interaction on these or the other ratings. Regarding fast track participants' preferences, we found that participants who conducted the study without the threat of a fine showed a significantly higher preference for being in the fast track in a future study, $F(3,1148)=31.51, p<.01$. There was no effect for the pledge, $F(2,1148)$ $=0.09, p=0.91$, or the interaction, $F(4,1148)=0.92, p=0.45$.

Lawfulness Interaction. As detailed earlier, in a follow-up study we had participants complete several scales that measured their tendency to follow or obey rules; we then aggregated these scores to a composite variable we termed "lawfulness" and used the 
Johnson-Neyman technique to estimate the effect of the pledge at different levels of lawfulness. This technique uses a bootstrapping method to identify the range of values on the moderating variable (lawfulness) in which the effect of the independent variable (pledge) on the dependent variable (overall cheating) is statistically significant $(p<.05)$. For the purposes of this analysis, we merged the conditions of the pledge with or without a reminder to one condition to create a binary variable of 0 (no pledge) and 1 (with pledge). As can be seen in Figure 6, we found that the pledge had a significant effect starting from the value of 6.78 on the lawfulness scale and above, which describes about $90 \%$ of our sample.

Figure 6. Slope (effect) of the pledge on increasing degrees of lawfulness (blue area shows effect significant at the .05 level).

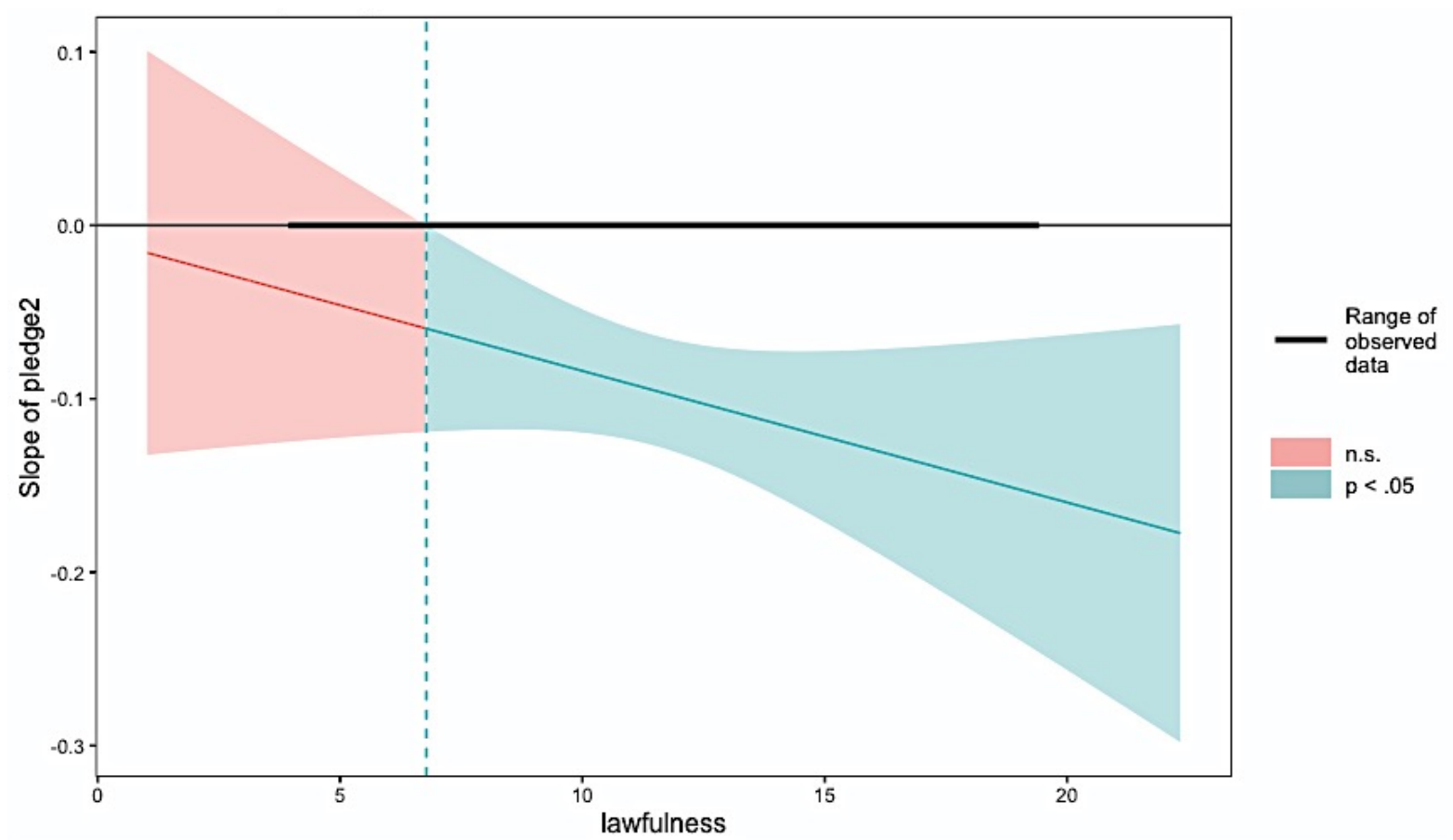

Cheating Extent. Finally, we examined whether the pledge and/or the fine affected participants who cheated to a large extent and claimed a very high score in their report. Figure 7 shows the percent of participants, in each condition, according to the percent of 
problems they reported as correct. As can be seen, and consistent with previously reported results, the mean in the control group (colored white) was the lowest, whereas the mean in the self-report group (colored lightest gray) was the highest. Accordingly, the distribution of reports in the conditions that included the pledge, fine, or both was lower (we analyzed this question regardless of whether the condition included a reminder). Most relevant, the percentage of "high extent cheater" (defined as $75 \%$ or higher) was largest among the selfreport group (32.2\%) and was considerably smaller when there was a pledge $(13 \%)$ or a fine $(13.2 \%)$; it was the smallest when there were both a pledge and a fine (5.4\%). These differences were statistically significant $-\mathrm{x}^{2}(4)=85.56, p<.001-$ and also remained significant and similar when the threshold for "high extent cheater" was defined anywhere between $60 \%-90 \%$. This suggests that the effects of the pledge and/or the fine were evident among participants who exhibited high degrees of cheating.

Figure 7. Distribution of percent of problems reports as solved between the conditions.

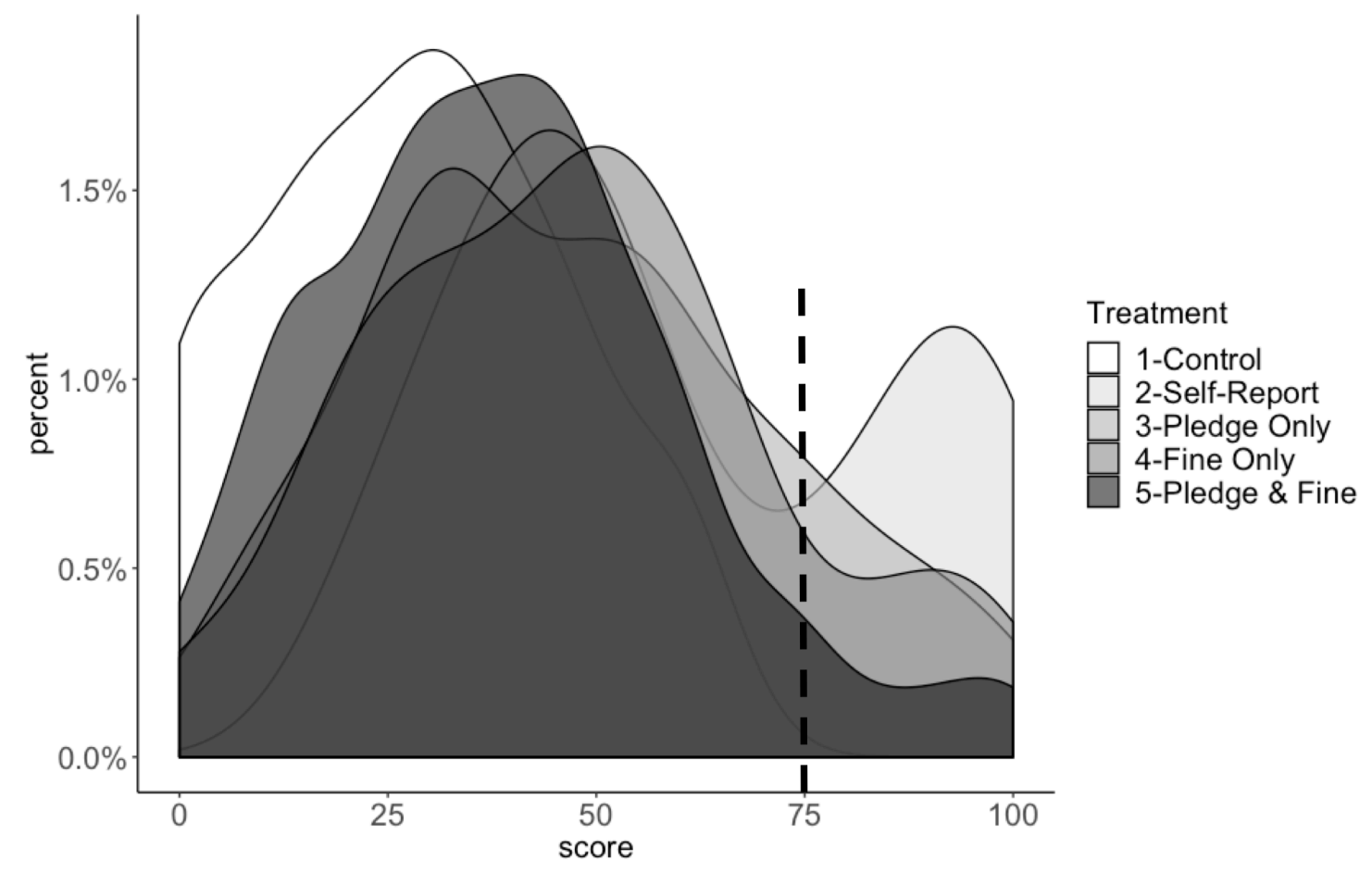




\section{Discussion}

We found that an ex-ante pledge can reduce dishonesty significantly, considerably, and even when compared to a (maximally possible) fine. In addition, the effect of the pledge did not seem to decay over the (relatively short) period of time we examined in this study. Reminding participants about their pledge in the middle of the time interval did not add to the reduction in cheating. The effect of the pledge seems not to be restricted to the highly lawful or obedient participants, as measured by the lawfulness scales used in the follow-up study. Moreover, this effect was also evident when specifically examining those who cheated to a larger extent than others. In the following, we discuss in more detail the theoretical and applied importance of each of these findings, as well as the long-term vision of using pledges in regulation policy.

\section{Expanding the Usage of Pledges}

The use of pledges in various legal and organizational contexts is on the rise, but the evidence on their efficacy across important dimensions is still scarce. Because we are interested in understanding how pledges could be used to replace or complement more restrictive commandand-control regulatory means, we focus on how honesty pledges can actually be used as a meaningful regulatory tool, even in traditional regulatory contexts. In many of the contexts where pledges were studied, they were used merely as a ceremonial oath that was supposed to demonstrate a general commitment to ethics (for a review, see, for example, de Bruin, 2016), but not to supplement or replace existing regulatory tools. However, the findings reported in this article derive from pledges that became a regulatory tool for areas in which regulatory supervision was usually required. This difference is very important, because it opens up the possibility for regulators to be able to use pledges as a legitimate policy instrument to replace existing regulatory means. To use pledges in this manner, we need to know with far greater certainty how they work, for how long they are active, and how they interact with other regulatory tools. 
Our study addresses several critical factors that could increase the utility of behavioralbased interventions in challenging regulatory contexts. The first factor is the ability of pledges to work side by side with fines, despite theories of crowding-out, which suggest that fines might undermine the influence of the individual's moral values on behavior, as discussed earlier (Atiq, 2013; Feldman \& Perez, 2012; Rode, Gómez-Baggethun, \& Krause, 2015). In our study, we used the maximal fine possible (elimination of all potential bonuses) and found no evidence for crowding out. However, in some cases fines could be larger, and other, more severe, sanctions (legal or administrative ones) may be used. We could not test such severe cases in our study, and additional studies could and should expand these findings to test whether and when could severe sanctions crowd-out the effect of a pledge. Nevertheless, our findings still provide useful conclusions, because the aim of responsive regulation is not to avoid the use of fines altogether, but rather to enhance the ability of regulators to use the optimal level of strictness relative to the likelihood of people's cooperation with certain regulatory interventions (e.g. Mascini \& Wijk, 2009). The main limitation of many behaviorally informed regulatory means is the lack of certainty associated with them (Black \& Baldwin, 2010). In other words, the fact that regulators cannot know in advance how many people will adhere to their interventions forces them to resort to the lowest common denominator (i.e., assume the worse about people) in the early stages, not giving softer regulatory means a chance (Cooter, 1998). The findings of the current study that suggest that fines and pledges could work together are therefore highly important to the ability to use these regulatory means in tandem, thereby enabling the use of pledges even in areas where regulators find some monitoring to be essential.

\section{Durability of the Effect of Pledges}

Our study is the first, that we are aware of, to test the effect of pledges over time and in sequential tasks, and not only in one-shot decisions. We found that the effect of pledges do not decay considerably over time and that reminding participants about their pledge half-way had 
no marginal contribution to their overall effect. This finding is especially encouraging in light of the classic argument about ethical numbing (e.g., Ayal et al., 2015). Nonetheless, in our studies, we did not see an overall decay in the effect of pledges, as some might predict based on the research on ethical awareness (VanSandt, Sheppard, \& Zappe, 2006). However, more studies are needed to better understand if and how the effect of pledges might decay over longer periods of time, as they could occur in real-life settings. Future research should also examine what happens when there are time intervals between when pledge is taken, and when the specific behavior that needs to be regulated actually occurs.

\section{Pledges and Heterogeneity}

Our study had some surprising findings. We predicted that a pledge, as a tool that increases awareness to the morality of honesty, would be more effective with people who had a stronger personal commitment to morality and ethics. Such interaction might have created a mismatch between the type of people that the state is interested in targeting with these new behavioral methods (i.e., people who have low personal morality and whose likelihood of dishonesty is higher) and the type of people whose personal commitment to behave ethically is more likely to have an impact on them (i.e., people who have high personal morality and would not have lied even without the pledge; Feldman \& Smith 2014). Instead, we found that the effect of pledges was in fact significant across individual differences in tendency to follow rules and instructions, as well as between people who chose to cheat to small vs. larger extents. The results of our study suggest that regulators' fear that people will cheat when given the opportunity to do so-which may justify their lower levels of trust in people in certain situations - is unfounded. Future research should focus on exploring additional individual differences.

\section{Trust and Beyond Compliance}


Perhaps the most important factor to discuss when analyzing the efficacy of pledges is the broader impact of their widespread use on the interaction between the state and regulatees; that is, after regulators are satisfied by the efficacy of pledges across the factors measured in this study (equal efficacy as fines, durability, lack of crowding-out, and ability to deal with heterogeneous populations). The ability of regulatory interventions to enhance trust is one of the most important goals of modern regulatory theory. When analyzing the pros and cons of using means such as pledges, we need to understand that the analysis should not be limited to comparing their short-term consequences but should also examine their ability to foster trust: when people feel themselves trusted by the government, they may then reciprocate by behaving in a more trustworthy manner (Hardin \& Offe ,1999; Murphy, 2008).

Since trust is so important for voluntary compliance (Murphy 2004), adopting regulatory means that are likely to lead to greater trust in the long term should be preferred over similar regulatory instruments that do not enhance trust, even if mean from the first kind, yield less compliance in the short run. The classic study of Braithwaite and Makkai (1994) on the regulation of Australian nursing homes demonstrates the contribution of instruments that make people feel trusted (as pledges could do, if they are designed properly)- their usage leads to the development of goodwill among regulatees as they learn to be more cooperative with authorities.

In many cases, regulators are interested not just in making sure that people merely comply by doing the bare minimum needed to avoid penalties but also want them to engage in what has been called "beyond compliance" (Gunningham, Kagan, \& Thornton, 2004). Beyond compliance refers to the activities that regulatees perform above and beyond what is expected of them by a strict interpretation of the law or regulation. Since in most contexts (e.g., when compliance is not a dichotomous behavior) beyond compliance is seen as a desirable type of behavior, the advantages of governance by pledges rather than by fines seems to be clear 
(Cooter, 2000). Additionally, the comparison of instruments will need to take account of additional positive externalities of pledges that are missing from the current discussion. Even if fines are a bit more effective, they create direct and indirect costs stemming both from their administration and their long-term harmful effects on the societal level of trust and intrinsic motivation for the general populace to engage in compliance and beyond compliance practices.

Important questions remain about the usage and effectiveness of pledges that need to be answered before they can relied upon more widely. First and foremost, there is a need for studies to continue and replicate the effect of pledges. The replication failure of the signing-atthe-top manipulation (Kristal et al., 2020) carries important implications for behaviorally driven policy making. Changing the placement of the signature is a common-sense-based approach, where the effect seems highly intuitive and easy to implement, which is why policy makers were so fast to accept such a costless change in how forms are designed (John, 2018). Changing public policy based on experimental findings needs to be done with caution and humility. For example, it is important to understand how pledges — which in our studies were done with regard to verifiable activities — would work with regard to activities whose post hoc verification is either costly or prohibitive (Gneezy, Kajackaite, \& Sobel, 2018). Future studies should be designed in such a way that individuals clearly understand where the line between compliance and noncompliance is drawn; tested assignments need to make it very clear what would constitute cheating. In reality, however, compliance decisions are far more ambiguous.

Therefore, the challenge of a well-executed pledge is to disambiguate, both descriptively and normatively, the obligations that people take upon themselves when making said pledge. The design of pledge texts should account for the potential negative contribution of ambiguity to ethical behavior by clarifying to people what is the ethical thing to do in a given context. Behavioral ethics tells us that many people engage in self-serving interpretations of both reality and the legal ordinance of a given situation (Dana, Weber, \& Kuang, 2007; 
Tenbrunsel et al., 2010), feeling that what they have done could account for compliance, even when in reality or according the legal framework, it does not (Feldman \& Teichman, 2011). Our paper proposes that ex-ante pledges could help circumvent these behavioral pitfalls and ensure that most people would behave in a more ethical manner, thus contributing more to the society's welfare, and fostering trust between governments and their public.

Acknowledgments: The research was supported by a research grant from the Israeli Democracy Institute (IDI) and the Israeli Ministry of Justice. We thank the IDI for its financial and professional support, and specifically to Daphna Aviram-Nitzan and Omer Slivansky. We also thank Tamar Ben-Meir and Adina Karpuj for their assistance in conducting the study. 


\section{References}

Anania, G., \& Nisticò, R. (2004). Public regulation as a substitute for trust in quality food markets: what if the trust substitute cannot be fully trusted? Journal of Institutional and Theoretical Economics, 160(4), 681-701.

Atiq, E. H. (2013). Why motives matter: Reframing the crowding out effect of legal incentives. Yale Law Journal, 123, 1070-1116.

Ayal, S., Gino, F., Barkan, R., \& Ariely, D. (2015). Three principles to REVISE people's unethical behavior. Perspectives on Psychological Science, 10(6), 738-741.

Ayres, I., \& Braithwaite, J. (1992). Responsive Regulation: Transcending the Deregulation Debate. London: Oxford University Press.

Bazerman, M. H., \& Gino, F. (2012). Behavioral ethics: Toward a deeper understanding of moral judgment and dishonesty. Annual Review of Law and Social Science, 8, 85104.

Beck, T., Bühren, C., Frank, B., \& Khachatryan, E. (2018). Can Honesty Oaths, Peer Interaction, or Monitoring Mitigate Lying? Journal of Business Ethics, 1-18. https://doi.org/10.1007/s10551-018-4030-z

Bews, N. F., \& Rossouw, G. J. (2002). A role for business ethics in facilitating trustworthiness. Journal of Business Ethics, 39, 377-390.

Black, J., \& Baldwin, R. (2010). Really responsive risk-based regulation. Law \& Policy, 32(2), 181-213.

Bowles, S., \& Polania-Reyes, S. (2012). Economic incentives and social preferences: substitutes or complements? Journal of Economic Literature, 50(2), 368-425.

Braithwaite, J., \& Makkai, T. (1994). Trust and compliance. Policing and Society: An International Journal, 4(1), 1-12.

Cagala, T., Glogowsky, U., \& Rincke, J. (2019). Content Matters: The Effects of Commitment Requests on Truth-Telling. Available at SSRN 3432445.

Carlsson, F., Kataria, M., Krupnick, A., Lampi, E., Löfgren, Å., Qin, P., \& Sterner, T. (2013). The truth, the whole truth, and nothing but the truth-A multiple country test of an oath script. Journal of Economic Behavior \& Organization, 89, 105-121.

Clark, S. J. (2003). Promise, Prayer and Identity. Tulsa Law Review, 38(4), 579-594.

Cohn, A., Fehr, E., \& Maréchal, M. A. (2014). Business culture and dishonesty in the banking industry. Nature, 516, 86-89. 
Cooter, R. (1998). Models of Morality in Law and Economics: Self-Control and SelfImprovement for the Bad Man of Holmes. Boston University Law Review, 78, $903-$ 930.

Cooter, R. (2000). Do good laws make good citizens? An economic analysis of internalized norms. Virginia Law Review, 86(8), 1577-1601;

Dana, J., Weber, R. A., \& Kuang, J. X. (2007). Exploiting moral wiggle room: experiments demonstrating an illusory preference for fairness. Economic Theory, 33(1), 67-80.

de Bruin, B. (2016). Pledging integrity: Oaths as forms of business ethics management. Journal of Business Ethics, 136(1), 23-42.

Erat, S., Gneezy, U. (2012). White lies. Management Science, 58(4), 723-33.

Esbensen, F. A., \& Osgood, D. W. (1999). Gang Resistance Education and Training (GREAT): Results from the national evaluation. Journal of Research in Crime and Delinquency, 36(2), 194-225.

Feldman, Y. (2018). The Law of Good People: Challenging States' Ability to Regulate Human Behavior. Cambridge: Cambridge University Press.

Feldman, Y., \& Perez, O. (2012). Motivating environmental action in a pluralistic regulatory environment: An experimental study of framing, crowding out, and institutional effects in the context of recycling policies. Law \& Society Review, 46(2), 405-442.

Feldman, Y., \& Smith, H. E. (2014). Behavioral equity. Journal of Institutional and Theoretical Economics, 170(1), 137-159.

Feldman, Y., \& Teichman, D. (2009). Are all legal probabilities created equal. NYUL Rev., 84, 980 .

Fine, A., Van Rooij, B., Feldman, Y., Shalvi, S., Scheper, E., Leib, M., \& Cauffman, E. (2016). Rule orientation and behavior: Development and validation of a scale measuring individual acceptance of rule violation. Psychology, Public Policy, and Law, 22(3), 314.

Frey, B. S. (2018). Illegal, immoral, fattening or what?: How deterrence and responsive regulation shape tax morale. In Bajada, C., \& Schneider, F. (Eds) (2005). Size, causes and consequences of the underground economy: An international perspective (pp. 1537). Routledge.

Gächter, S., \& Schulz, J. F. (2016). Intrinsic honesty and the prevalence of rule violations across societies. Nature, 531(7595), 496-499.

Galbiati, R., \& Vertova, P. (2014). How laws affect behavior: Obligations, incentives and cooperative behavior. International Review of Law and Economics, 38, 48-57. 
Gerlach, P., Teodorescu, K., \& Hertwig, R. (2019). The truth about lies: A meta-analysis on dishonest behavior. Psychological Bulletin, 145(1), 1-44.

Gilligan, G. (2018). The Hayne royal commission and trust issues in the regulation of the Australian financial sector. Law and Financial Markets Review, 12(4), 175-185.

Gunningham, N., Kagan, R. A., \& Thornton, D. (2004). Social license and environmental protection: why businesses go beyond compliance. Law \& Social Inquiry, 29(2), 307341.

Gneezy, U., Kajackaite, A., \& Sobel, J. (2018). Lying Aversion and the Size of the Lie. American Economic Review, 108(2), 419-53. Hardin, R., \& Offe, C. (1999). Democracy and trust. Cambridge University Press. Hardin, R. (2002). The Russell Sage Foundation series on trust. Trust and trustworthiness. Russell Sage Foundation.

Jacobsen, C., Fosgaard, T. R., \& Pascual-Ezama, D. (2018). Why do we lie? A practical guide to the dishonesty literature. Journal of Economic Surveys, 32(2), 357-387.

Jacquemet, N. (2019). Who'll stop lying under oath? Empirical evidence from Tax Evasion Games. Retrieved from https://halshs.archives-ouvertes.fr/halshs-02159905 Jacquemet, N., James, A., Luchini, S., Murphy, J., \& Shogren, J. F. (2019). Lying and Shirking Under Oath. Economic Science Institute Working Paper 19-19. Retrieved from https://digitalcommons.chapman.edu/esi working papers/278/

John, P. (2018). How far to nudge?: assessing behavioral public policy. Edward Elgar Publishing.

Kemper, N., Nayga, R. M. Jr., Popp, J., \& Bazzani, C. (2016). The effects of honesty oath and consequentiality in choice experiments. Paper presented at the meeting of Agricultural \& Applied Economics Association, Boston.

Knoll, J. L., Arthur, R. L. (1994). Examination under Oath - Illuminating the Cause and Extent of Property Insurance Losses, Brief, 23(2), 26-60.

Kristal, A. S., Whillans, A. V., Bazerman, M. H., Gino, F., Shu, L. L., Mazar, N., \& Ariely, D. (2020). Signing at the beginning versus at the end does not decrease dishonesty. Proceedings of the National Academy of Sciences, 117(13), 7103-7107.

Kucher, M., \& Götte, L. (1998). Trust Me. An empirical analysis of taxpayer honesty. FinanzArchiv / Public Finance Analysis, 55(3), 429-444. 
Lewis, A., Carrera, S., Cullis, J., \& Jones, P. (2009). Individual, cognitive and cultural differences in tax compliance: UK and Italy compared. Journal of Economic Psychology, 30(3), 431-445.

Mascini, P., \& Wijk, E. V. (2009). Responsive regulation at the Dutch Food and Consumer Product Safety Authority: an empirical assessment of assumptions underlying the theory. Regulation \& Governance, 3(1), 27-47.

Mazar, N., Amir, O., \& Ariely, D. (2008). The dishonesty of honest people: A theory of selfconcept maintenance. Journal of marketing research, 45(6), 633-644.

Möllering, G. (2006). Trust: Reason, Routine, Reflexivity. Elsevier: Emerald Group Publishing.

Moore, C., Detert, J. R., Klebe Treviño, L., Baker, V. L., \& Mayer, D. M. (2012). Why employees do bad things: Moral disengagement and unethical organizational behavior. Personnel Psychology, 65(1), 1-48.

Moyson, S. (2017). Trust in Regulatory Regimes by Six, F. \& Verhoest, K., Cheltenham, UK: Edward Elgar. Journal of Trust Research, 7(2), 226-229.

Murphy, K. (2004). The role of trust in nurturing compliance: A study of accused tax avoiders. Law and human behavior, 28(2), 187-209.

Murphy, K. (2008). Enforcing tax compliance: to punish or persuade? Economic analysis and policy, 38(1), 113-135.

Peer, E., Brandimarte, L., Samat, S., \& Acquisti, A. (2017). Beyond the Turk: Alternative platforms for crowdsourcing behavioral research. Journal of Experimental Social Psychology, 70, 153-163.

Rode, J., Gómez-Baggethun, E., Krause, T. (2015). Motivation crowding by economic incentives in conservation policy: A review of the empirical evidence. Ecological Economics, 117(C), 270-282.

Shalvi, S., Eldar, O., \& Bereby-Meyer, Y. (2012). Honesty requires time (and lack of justifications). Psychological Science, 23(10), 1264-1270.

Shu, L. L., Mazar, N., Gino, F., Ariely, D., \& Bazerman, M. H. (2012). Signing at the beginning makes ethics salient and decreases dishonest self-reports in comparison to signing at the end. Proceedings of the National Academy of Sciences, 109, 1519715200.

Steen, T. P. S., Rutgers, M., R. (2011). The double-edged sword. Public Management Review, 13(3), 343-361. 
Tenbrunsel, A. E., Diekmann, K. A, Wade-Benzoni, K. A., \& Bazerman, M. H. (2010). The ethical mirage: A temporal explanation as to why we are not as ethical as we think we are. Research in Organizational Behavior, 30, 153-173.

Tenbrunsel, A. E., \& Messick, D. M. (1999). Sanctioning systems, decision frames, and cooperation. Administrative Science Quarterly, 44(4), 684-707.

Torgler, B. (2003). Tax morale, rule-governed behaviour and trust. Constitutional Political Economy, 14(2), 119-140.

Tyler, T. R. (2006). Why people obey the law. Princeton University Press. Tyran, J. R., \& Feld, L. P. (2006). Achieving compliance when legal sanctions are nondeterrent. scandinavian Journal of Economics, 108(1), 135-156.

VanSandt, C. V., Shepard, J. M., Zappe, S. M. (2006). An examination of the relationship between ethical work climate and moral awareness. Journal of Business Ethics, 68(4), 409-432.

Verschuere, B., Meijer, E. H., Jim, A., Hoogesteyn, K., Orthey, R., McCarthy, R. J., ... \& Barbosa, F. (2018). Registered replication report on Mazar, Amir, and Ariely (2008). Advances in Methods and Practices in Psychological Science, 1(3), 299-317. 